\title{
Spectro-Electrochemical Examination of the Formation of Dimethyl Carbonate from CO and Methanol at Different Electrode Materials
}

\author{
Marta C. Figueiredo, ${ }^{\dagger, \S}$ Vinh Trieu, ${ }^{\ddagger}$ Stefanie Eiden, ${ }^{\ddagger}$ and Marc T. M. Koper*,† \\ ${ }^{\dagger}$ Leiden Institute of Chemistry, Leiden University, P.O. Box 9502, 2300 RA Leiden, The Netherlands \\ ${ }^{\ddagger}$ Covestro Deutschland AG, 51365 Leverkusen, Germany
}

\section{Supporting Information}

ABSTRACT: In this work, we report a fundamental mechanistic study of the electrochemical oxidative carbonylation of methanol with $\mathrm{CO}$ for the synthesis of dimethyl carbonate on metallic electrodes at low overpotentials. For the first time, the reaction was shown to take place on the metallic catalysts without need of oxidized metals or additives. Moreover, in-situ spectroelectrochemical techniques were applied to this electrosynthesis reaction in order to reveal

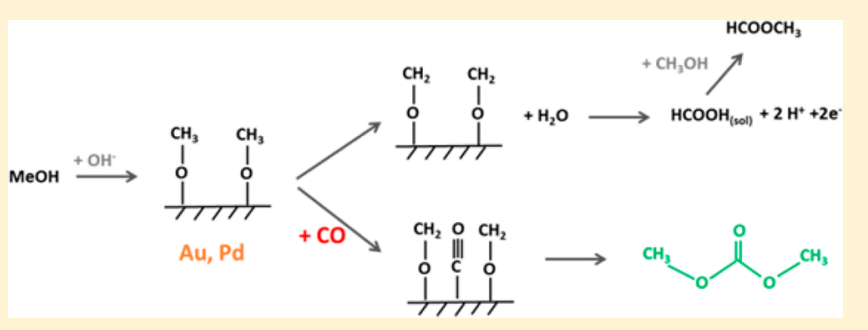
the reaction intermediates and to shed light into the reaction mechanism. Fourier transformed infrared spectroscopy was used with different electrode materials ( $\mathrm{Au}, \mathrm{Pd}, \mathrm{Pt}$, and $\mathrm{Ag})$ to assess the effect of the electrode material on the reaction and the dependence of products and intermediates on the applied potentials. It was observed that the dimethyl carbonate is only formed when the electrode is able to decompose/oxidize $\mathrm{MeOH}$ to form (adsorbed) methoxy groups that can further react with CO to dimethyl carbonate. Furthermore, the electrode needs to adsorb $\mathrm{CO}$ not too strongly; otherwise, further reaction will be inhibited because of surface poisoning by $\mathrm{CO}$.

\section{INTRODUCTION}

Many industrial chemical processes involve a high-energy demand (often still derived from fossil fuels), toxic reactants, and the production of high amounts of waste. Therefore, the development of more efficient, less hazardous technologies, based on renewable energies, has become one of the most challenging topics for chemical synthesis. For achieving these goals, the combination of catalysis with electrochemical methods, that is, electrocatalysis, can play a very important role. With electrochemical methods, toxic and dangerous chemicals can be replaced with clean electrons, the efficiency and selectivity of the reactions can be tuned by choosing the applied potential, and more importantly, the energy used can come from renewable sources like wind or solar.

Dimethyl carbonate (DMC) is an important chemical building block used in many industrial synthesis reactions because of its low ecotoxicity and bioaccumulation. ${ }^{2}$ Moreover, it is also widely used as a fuel additive and as a polar solvent, ${ }^{3}$ increasing its needs of production. The industrial synthesis of DMC is based on oxidative carbonylation. ${ }^{2}$ However, because of the high demand of this compound, the development of new sustainable methodologies (direct synthesis, less waste reagents, green energy) is much desired, especially in a moment that electrochemical production processes using gas diffusion electrodes are already established in chemical industry, as for example, the oxygen-depolarized cathodes in $\mathrm{HCl}$ electrolysis. ${ }^{4}$

Synthesis processes based on the carbonylation of methanol have been described in the literature. ${ }^{5-12}$ Most of these studies use heterogeneous catalysts to achieve the carbonylation of methanol with $\mathrm{CO}$ over solid catalysts such as $\mathrm{CuY},{ }^{6,7} \mathrm{Cu}-$
$\mathrm{Pd}^{9,11}$ and activated $\mathrm{Au}^{8}{ }^{8}$ However, most processes still require high temperatures and pressures in order to achieve reactivity. Concerning electrochemical methodologies, the number of studies is more limited. ${ }^{13-15} \mathrm{MeOH}$ carbonylation with $\mathrm{CO}$ was achieved with $\mathrm{Pd}^{14}$ and $\mathrm{Au}^{13}$ based electrodes. For $\mathrm{Au} /$ carbon electrodes, the application of high potentials $>+1.3 \mathrm{~V}$ was required indicating that $\mathrm{Au}^{3+}$ was the active species for the formation of DMC. However, the activity gradually decreased at $+1.5 \mathrm{~V}$, and the authors suggested that DMC is produced by indirect electrochemical carbonylation mediated by the $\mathrm{Au}^{3+}$ / $\mathrm{Au}^{+}$redox reaction. ${ }^{13}$

Similar findings were described for Pd/C catalysts. ${ }^{14}$ In this case, the indirect electrochemical carbonylation of methanol and $\mathrm{CO}$ was promoted by the presence of an $\mathrm{XBr}$ mediator, with $\mathrm{X}=\mathrm{Li}, \mathrm{Na}$, and tetrabutylammonium. It was suggested that the $\mathrm{XBr}$ promoter is electrochemically oxidized to $\mathrm{Br}_{2}$ at the anode and that the latter works as an oxidant for the oxidative carbonylation. The main drawback of the existing studies comes from the lack of the direct identification of reaction intermediates, their interaction with the electrode materials, and their dependence on the applied potential.

In this work, we investigate the fundamental aspects of the mechanism of the electrocatalytic synthesis of DMC from $\mathrm{MeOH}$ and $\mathrm{CO}$ on precious metal electrodes ( $\mathrm{Au}, \mathrm{Pd}, \mathrm{Pt}$, and $\mathrm{Ag}$ ). By means of in-situ Fourier transform infrared spectroscopy (FTIR), the solvent decomposition, reaction intermediates, and products were analyzed, and their dependence on the

Received: August 3, 2017

Published: September 20, 2017 
applied potential and electrode material was investigated. In contrast to previous studies, ${ }^{13}$ a low overpotential for the production of DMC was achieved $(0.5 \mathrm{~V})$, which reduces energy losses and increases the lifetime of the electrode. It was observed that the DMC is only formed when the electrode is able to decompose/oxidize $\mathrm{MeOH}$ to form (adsorbed) methoxy groups (having methyl formate as side product as a consequence) that can further react with $\mathrm{CO}$ to $\mathrm{DMC}$. Furthermore, the electrode needs to adsorb $\mathrm{CO}$ not too strongly, otherwise further reaction will be inhibited because of surface poisoning by $\mathrm{CO}$. These results give, for the first time, a detailed view on the reaction intermediates and their dependence on the electrode material and can contribute to the development of new and more effective processes for the synthesis of DMC.

\section{RESULTS AND DISCUSSION}

Electrochemical Formation of DMC on Au Electrodes. Cyclic voltammograms (CV) in $0.1 \mathrm{M} \mathrm{LiClO}_{4}$ in $\mathrm{MeOH}$, with and without $\mathrm{CO}$ atmosphere, were obtained for the $\mathrm{Au}$ electrode to assess the electrochemical window and the presence of a possible faradaic process (Figure 1). The CV

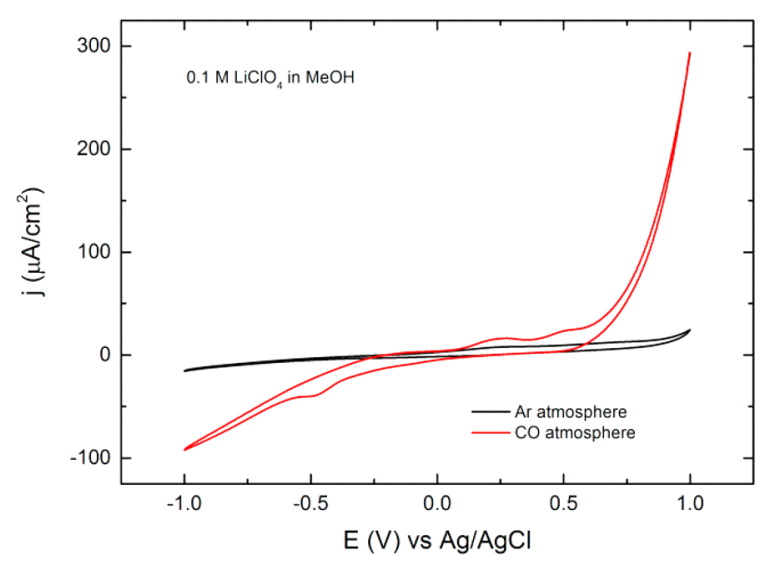

Figure 1. CVs obtained at the Au electrode in $0.1 \mathrm{M} \mathrm{LiClO}_{4}$ in $\mathrm{MeOH}$ in $\mathrm{Ar}$ (black line) and $\mathrm{CO}$ (red line) atmosphere, scan rate of $100 \mathrm{mV} /$ s.

shows that the Au electrode has a potential window of $2 \mathrm{~V}$ (from -1 to $1 \mathrm{~V}$ ). The potential window is limited by residual water reduction at negative potentials and by $\mathrm{MeOH}$ decomposition at anodic potentials.

When $\mathrm{CO}$ is bubbled through the solution, the measured $\mathrm{CV}$ is significantly different. In the positive-going sweep, two oxidation waves are observed followed by a steep increase in current at potentials higher than $0.6 \mathrm{~V}$. As these oxidation processes are not visible in the absence of $\mathrm{CO}$, they are most likely related with $\mathrm{CO}$ oxidation or $\mathrm{CO}$ insertion into $\mathrm{MeOH}$ or with the formation of other products, as it will be clarified later with the FTIR results.

At negative potentials, reduction currents were obtained. We should bear in mind that the CVs were started at $0 \mathrm{~V}$ and that the potentials were scanned first positively up to $1 \mathrm{~V}$ and then back to negative potentials. As it is indicated by the FTIR spectra shown in the Supporting Information (Figure S1), the reduction processes correspond to the reduction of the products formed oxidatively. However, as the aim of this work is the oxidative carbonylation of $\mathrm{MeOH}$ with $\mathrm{CO}$ for the spectroelectrochemical measurements, we concentrate on potentials from 0 to $1 \mathrm{~V}$.

To look into the possible decomposition intermediates and products from $\mathrm{MeOH}$ at the $\mathrm{Au}$ electrode, FTIR spectra in $\mathrm{Ar}$ atmosphere were taken (Figure 2A).

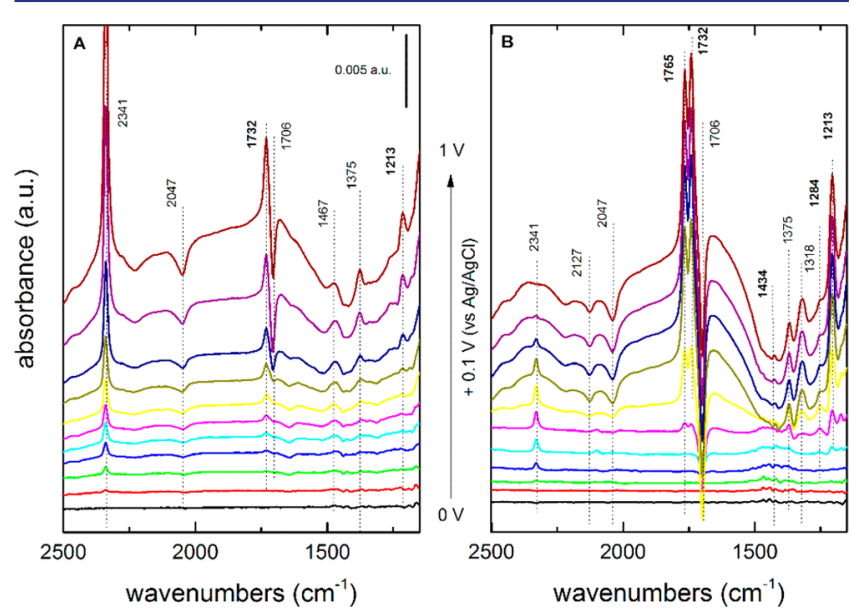

Figure 2. Spectra at different applied potentials (indicated in the figure) for the $\mathrm{Au}$ electrode in (A) $\mathrm{Ar}$ and (B) $\mathrm{CO}$ atmosphere in $\mathrm{MeOH}$ with $0.1 \mathrm{M} \mathrm{LiClO}_{4}$ as supporting electrolyte.

The results in Figure 2A show that $\mathrm{MeOH}$ decomposition/ oxidation starts at low potential, around $0.2 \mathrm{~V}$. At this potential, a positive band appears at $2341 \mathrm{~cm}^{-1}$ because of the presence of $\mathrm{CO}_{2}$ in the thin layer from $\mathrm{MeOH}$ oxidation. At $0.4 \mathrm{~V}$, another positive band at $1732 \mathrm{~cm}^{-1}$ starts being observed. This band, together with a band of lower intensity at $1213 \mathrm{~cm}^{-1}$, can be attributed to the formation of methyl formate (see Figure S3 for transmission spectra for product identification). Methyl formate is known as one of the products of direct oxidation of $\mathrm{MeOH}$ at platinum surfaces in aqueous media. ${ }^{16}$ In aqueous solution, $\mathrm{MeOH}$ dehydrogenation occurs to form a methoxy intermediate which is oxidized to formaldehyde. Formaldehyde is rapidly hydrated to methylene glycol that is then oxidized further to formic acid that reacts with $\mathrm{MeOH}$ to form methyl formate. ${ }^{16}$ As methyl formate is also a main product of methanol decomposition/oxidation in the present conditions, we can assume that a similar reaction mechanism is taking place at the $\mathrm{Au}$ electrode when $\mathrm{MeOH}$ is the solvent, especially because the solvent is not dry so that residual amounts of water allow the reaction to take place. Other bands present in the spectra $\left(2047,1706,1467,1375 \mathrm{~cm}^{-1}\right)$ are related with the solvent and supporting electrolyte or from the interference of both (see transmission spectra in Figure S2). The bands at 2047 and $1467 \mathrm{~cm}^{-1}$ are due to the $\mathrm{CH}$ overtone and $\mathrm{C}-\mathrm{H}$ bending from $\mathrm{MeOH}$, respectively. Interestingly, the band at $1706 \mathrm{~cm}^{-1}$ is observed for the spectra containing the supporting electrolyte, $\mathrm{LiClO}_{4}$. This band is most likely due to the spontaneous formation of lithium methoxide when $\mathrm{LiClO}_{4}$ is added to methanol. ${ }^{17}$ This intermediate is then consumed to form the product of $\mathrm{MeOH}$ decomposition/ oxidation, that is, methyl formate.

When the solution is saturated with $\mathrm{CO}$, the obtained spectra show a set of new bands (Figure 2B). Together with the bands described previously for methyl formate, three new bands are visible at 1761,1434 , and $1286 \mathrm{~cm}^{-1}$. These bands are due to the formation of DMC as confirmed by the transmission spectra for DMC in $\mathrm{MeOH}$ (Figure S2). In fact, the formation 

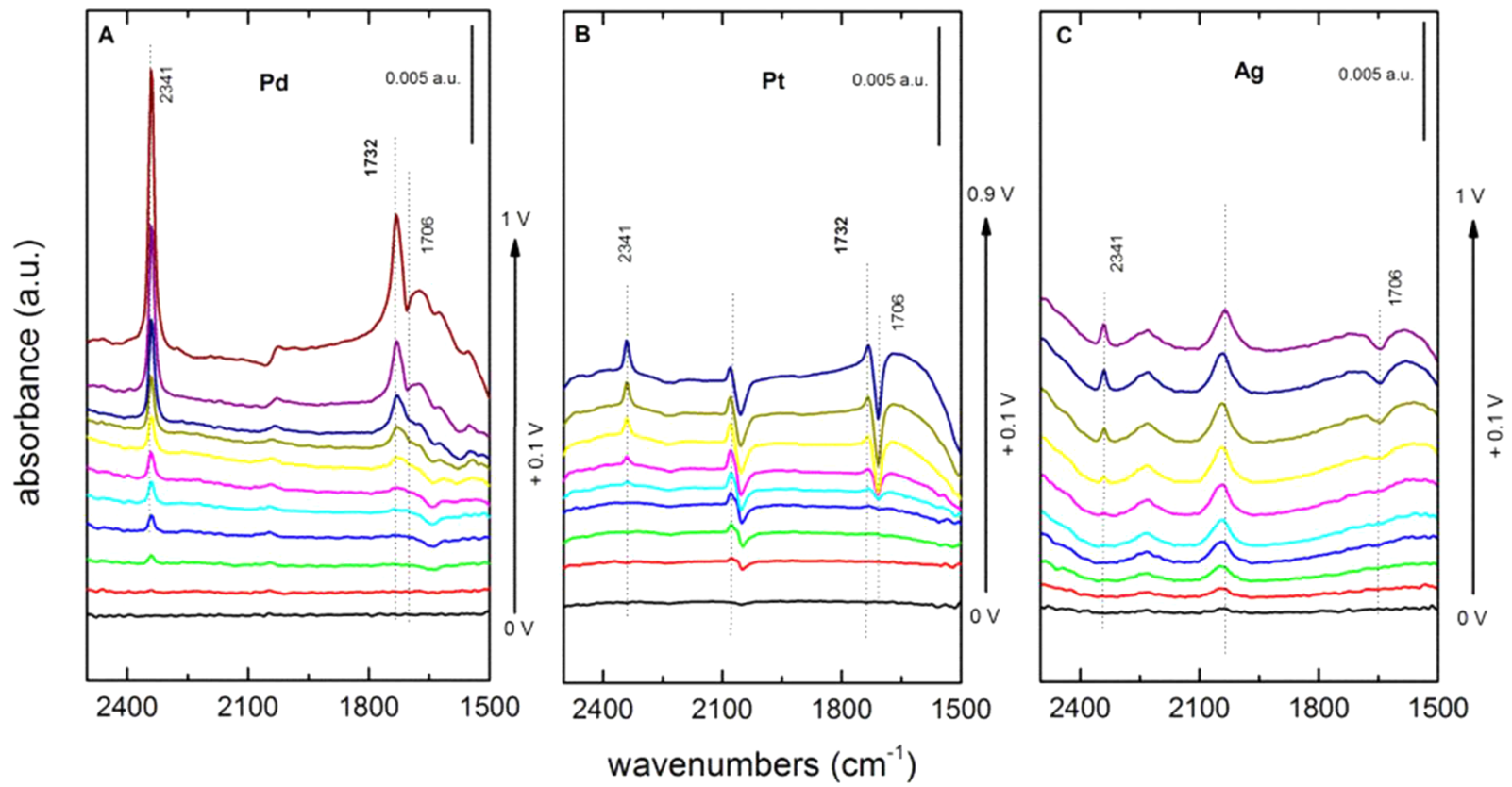

Figure 3. Spectra at different applied potentials (indicated in the figure) for the $\mathrm{Pd}, \mathrm{Pt}$, and $\mathrm{Ag}$ electrodes in $\mathrm{Ar}$ atmosphere in $\mathrm{MeOH}$ with $0.1 \mathrm{M}$ $\mathrm{LiClO}_{4}$ as supporting electrolyte.
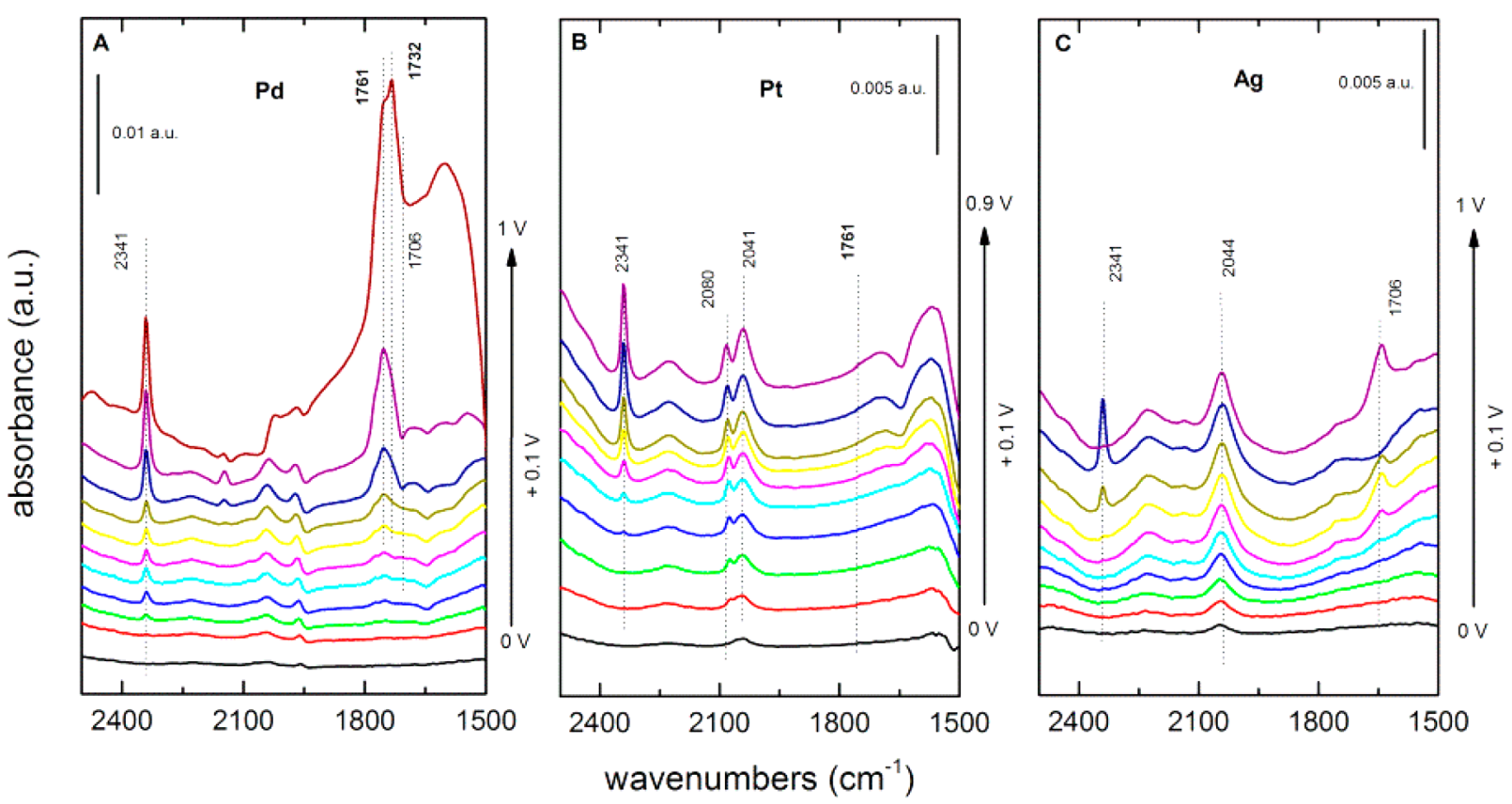

Figure 4. Spectra at different applied potentials (indicated in the figure) for the $\mathrm{Pd}$, $\mathrm{Pt}$, and $\mathrm{Ag}$ electrodes in $\mathrm{CO}$ saturated atmosphere in $\mathrm{MeOH}$ with $0.1 \mathrm{M} \mathrm{LiClO}_{4}$ as supporting electrolyte.

of DMC from $\mathrm{CO}$ and methanol has already been described for Au electrodes. ${ }^{13}$ However, in that paper, a significantly higher applied potential was necessary for achieving conversion to $\mathrm{DMC}$, and the presence of metal oxides was claimed to be required. In our experiment, the formation of DMC takes place at potentials as low as $0.4 \mathrm{~V}$ before the formation of $\mathrm{Au}$ oxides, which starts at potentials higher than $1 \mathrm{~V}$ (vs $\mathrm{Ag} / \mathrm{AgCl})$. The spectra also show a negative band at $2127 \mathrm{~cm}^{-1}$ revealing the consumption of $\mathrm{CO}$ at the interface. Interestingly, the band for $\mathrm{CO}_{2}$ at $2341 \mathrm{~cm}^{-1}$ is much lower in intensity when $\mathrm{CO}$ is bubbled through the solution, although both $\mathrm{CO}$ and $\mathrm{MeOH}$ should also be oxidized to $\mathrm{CO}_{2}$. This suggests that $\mathrm{MeOH}$ oxidation to $\mathrm{CO}_{2}$ is inhibited in this case and that $\mathrm{CO}$ is preferentially taking part in the carbonylation reaction instead of being oxidized.

Effect of the Electrode Material. Aiming to understand the reaction mechanism for the formation of DMC from $\mathrm{MeOH}$ and $\mathrm{CO}$ and its dependence on the electrode material, experiments with $\mathrm{Pd}, \mathrm{Pt}$, and $\mathrm{Ag}$ electrodes were carried out. The spectra for these materials as a function of the applied potential for the blank solutions $\left(0.1 \mathrm{M} \mathrm{LiClO}_{4}\right.$ in $\left.\mathrm{MeOH}\right)$ and in $\mathrm{CO}$ atmosphere are presented in Figures 3 and 4.

The results in Figure 3 show some differences for $\mathrm{MeOH}$ decomposition/oxidation for the studied materials. For the $\mathrm{Pd}$ 
electrode (Figure 3A), the obtained products are very similar to those described for Au (Figure 2A). The spectra show bands for $\mathrm{CO}_{2}\left(2341 \mathrm{~cm}^{-1}\right)$ and methyl formate $\left(1732 \mathrm{~cm}^{-1}\right)$. The band for $\mathrm{CO}_{2}$ starts being observed at lower potential (around $0.2 \mathrm{~V}$ ) than methyl formate, the formation of which begins at around $0.5 \mathrm{~V}$. For Pt (Figure $3 \mathrm{~B}$ ), the same products are also observed at higher potential: 0.5 and $0.6 \mathrm{~V}$, for $\mathrm{CO}_{2}$ and methyl formate, respectively. Yet, another important band is observed, a bipolar band centered at $2041 \mathrm{~cm}^{-1}$, characteristic of an adsorbed species on the electrode surface. According to the transmission spectra (Figure S1), this band can be attributed to $\mathrm{MeOH}$ ( $\mathrm{CH}$ vibration overtones) as it is observed in the transmission spectra of the solvent itself, suggesting that $\mathrm{MeOH}$ is strongly adsorbed on the Pt electrode. For Ag (Figure 3C), no methyl formate is observed, and the band for $\mathrm{CO}_{2}$ is very small and only visible at potentials higher than $0.7 \mathrm{~V}$. However, $\mathrm{Ag}$ also shows a band for adsorbed $\mathrm{MeOH}$ at low potentials.

In the presence of $\mathrm{CO}$ (Figure 4), the three materials also show different characteristics toward the formation of DMC. The only material that shows the formation of $\mathrm{DMC}$ is $\mathrm{Pd}$ (Figure 4A), as observed by the presence of the band at 1761 $\mathrm{cm}^{-1}$. For Pt and Ag (Figure $4 \mathrm{~B}$ and $\mathrm{C}$ ), the band at 1761 $\mathrm{cm}^{-1}$ is absent suggesting that DMC formation does not occur on these materials, at least not in the potential range used in this study. Not surprisingly, the results suggest that $\mathrm{Pt}$ is strongly blocked by the adsorption of $\mathrm{CO}$ as evidenced by the band at $2080 \mathrm{~cm}^{-118}$ and that the main reaction product is $\mathrm{CO}_{2}$ from both $\mathrm{CO}$ and $\mathrm{MeOH}$ oxidation. In the case of $\mathrm{Ag}$, the results for $\mathrm{CO}$ atmosphere are very similar to those in $\mathrm{Ar}$ atmosphere, and the main identified bands correspond to the adsorption of $\mathrm{MeOH}$ and $\mathrm{CO}_{2}$ because of mild oxidation of $\mathrm{MeOH}$ at this surface.

On the basis of these results, we can suggest that there is a catalytic dependence on the electrode material for the synthesis of DMC from $\mathrm{MeOH}$ and CO. Materials like Pt, which bond CO too strongly, do not form DMC as the surface is blocked by the strong adsorbate, and the reaction cannot take place. On the other hand, $\mathrm{Ag}$ seems to be also blocked by strong adsorbates but in this case from $\mathrm{MeOH}$ inhibiting further reactions. Ag does not seem to adsorb $\mathrm{CO}$ under these conditions. Pd and Au have moderated adsorption energies for $\mathrm{CO}$ allowing it to be at the surface but not too strongly adsorbed, so that $\mathrm{CO}$ can further react and proceed with the carbonylation of $\mathrm{MeOH}$. Another interesting observation is that both $\mathrm{Pd}$ and $\mathrm{Au}$ have methyl formate as product from $\mathrm{MeOH}$ decomposition/oxidation, suggesting that methyl formate is an important byproduct of the electrocatalytic synthesis of DMC.

Isotopically Labeled CO. Methyl formate has been described as a good carbonylation agent in homogeneous catalysts, including DMC synthesis. ${ }^{20}$ However, in the conditions described in this work, if methyl formate was the carbonylation agent for the reaction, it would be expected that $\mathrm{DMC}$ would have been found also in the absence of CO. To shed some light on the carbonylation agent, experiments with isotopically labeled $\mathrm{CO}$ were performed to ensure its participation in the reaction. The Au electrode was chosen for these experiments as it shows the most intense bands for DMC. We should bear in mind that FTIR experiments in the thin-layer configuration are not quantitative, as the thin-layer thickness can be different from electrode to electrode. Nevertheless, the relative intensity of two bands should be proportional to the relative amount of the products. Comparing the bands of $\mathrm{CO}_{2}$ and $\mathrm{DMC}$ in the spectra for $\mathrm{Au}$ and for $\mathrm{Pd}$, for $\mathrm{Au}$ the DMC bands are significantly more intense than the $\mathrm{CO}_{2}$ bands, suggesting that $\mathrm{Au}$ is more active and selective for the electrosynthesis reaction than $\mathrm{Pd}$.

The results for the Au electrode in $0.1 \mathrm{M} \mathrm{LiClO}_{4}$ in $\mathrm{MeOH}$ with ${ }^{13} \mathrm{CO}$ are presented in Figure 5. The spectra show bands at

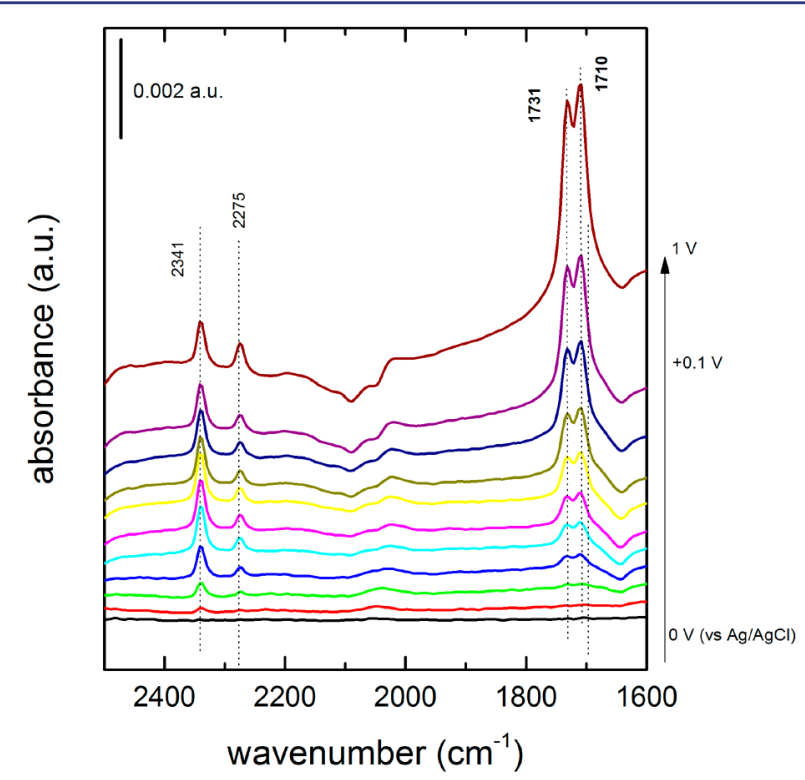

Figure 5. Spectra at different applied potentials (indicated in the figure) for the $\mathrm{Au}$ electrode in ${ }^{13} \mathrm{CO}$ saturated atmosphere in $\mathrm{MeOH}$ with $0.1 \mathrm{M} \mathrm{LiClO}_{4}$ as supporting electrolyte.

2341, 2275, 1731, and $1710 \mathrm{~cm}^{-1}$ corresponding to ${ }^{12} \mathrm{CO}_{2}$, ${ }^{13} \mathrm{CO}_{2}$, methyl formate, and ${ }^{12} \mathrm{DMC}$, respectively. The band at $2341 \mathrm{~cm}^{-1}$ increases in intensity from $0.2 \mathrm{~V}$ in accordance with Figure 2 and corresponds to the formation of ${ }^{12} \mathrm{CO}_{2}$ from the oxidation of $\mathrm{MeOH}$. At slightly higher potentials $(0.3 \mathrm{~V})$, the band for ${ }^{13} \mathrm{CO}_{2}$ is also observed, corresponding to the oxidation of ${ }^{13} \mathrm{CO}$. Around $0.4 \mathrm{~V}$, two additional bands can be observed, one at $1731 \mathrm{~cm}^{-1}$, previously identified as methyl formate (Figure S1), and a second band at $1710 \mathrm{~cm}^{-1}$. The latter is due to the formation of ${ }^{13} \mathrm{DMC}$ as it presents a shift of about $50-60$ $\mathrm{cm}^{-1}$ in accordance with the expected shift for the replacement of ${ }^{12} \mathrm{C}$ with ${ }^{13} \mathrm{C}$. No band at $1761 \mathrm{~cm}^{-1}$ is observed in the spectra showing that all the formed DMC is coming from the reaction of ${ }^{12} \mathrm{CO}$ with $\mathrm{MeOH}$ and not from methyl formate.

Reaction Scheme. The results presented earlier show that with the appropriate catalyst the formation of DMC from the electrocatalytic reaction of $\mathrm{MeOH}$ and $\mathrm{CO}$ can occur at low overpotentials. For this reaction to take place, the electrode should bind $\mathrm{CO}$ not too strongly in order to avoid surface poisoning and blockage (like for $\mathrm{Pt}$ ), but it should still be able to oxidize/decompose methanol. The importance of $\mathrm{MeOH}$ decomposition on the surface is supported by the fact that, if methyl formate is not obtained as product from $\mathrm{MeOH}, \mathrm{DMC}$ is also not observed as a product (such as for $\mathrm{Ag}$, for example). The experiments with isotopically labeled CO clearly show that methyl formate does not take place in the formation of DMC, although DMC is only produced if the metal oxidizes $\mathrm{MeOH}$ to methyl formate. As mentioned earlier, it has been reported that in the direct oxidation of methanol on platinum electrodes ${ }^{16}$ the formation of methyl formate involves the formation of methoxy groups on the electrode surface. Methoxy groups have also been reported as important intermediates for the synthesis 
of DMC from methanol gas phase catalysis. ${ }^{8}$ Therefore, we can relate the capability of the metal to form methyl formate with its ability to form methoxy groups, explaining the higher catalytic activity for DMC formation for metals that oxidize $\mathrm{MeOH}$ to methyl formate. Methyl formate is a side product from the reaction but also an indicator of the catalytic properties of the metal toward the formation of DMC in the presence of $\mathrm{CO}$. On the basis of these findings, we suggest that the electrocatalytic reaction forming DMC takes place if both methoxy and $\mathrm{CO}$ are (not too strongly) adsorbed on the electrode surface, as illustrated in Scheme 1.

Scheme 1. Reaction Scheme for the Electrosynthesis of DMC from Methanol and CO on Au and Pd Electrodes

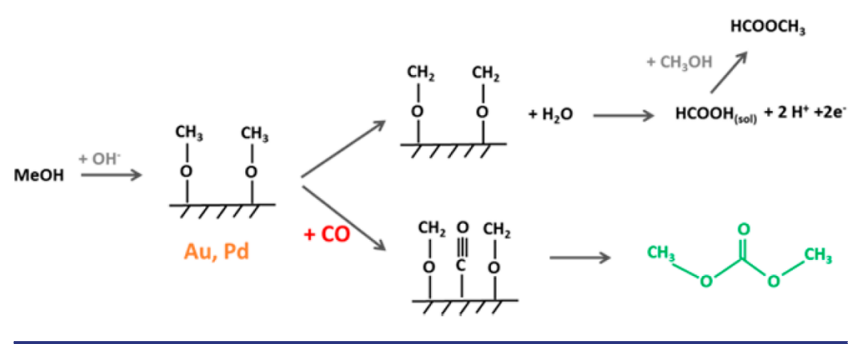

\section{CONCLUSIONS}

With this work, we show that the electrochemical synthesis of dimethyl carbonate from $\mathrm{CO}$ and methanol is very dependent on the electrode material properties toward the adsorption and stabilization of reaction intermediates such as methoxy groups. By investigating different electrode materials, it was observed that materials like $\mathrm{Pt}$, which bond $\mathrm{CO}$ too strongly, do not form $\mathrm{DMC}$ as the surface is blocked by the strong adsorbate, and the reaction cannot take place. On the other hand, Ag seems to be also blocked by strong adsorbates but in this case from $\mathrm{MeOH}$ inhibiting further reactions. Ag does not seem to adsorb $\mathrm{CO}$ under these conditions. Both $\mathrm{Pd}$ and $\mathrm{Au}$ have moderated adsorption energies for $\mathrm{CO}$ allowing it to be at the surface but not too strongly adsorbed, so that $\mathrm{CO}$ can further react and proceed with the carbonylation of $\mathrm{MeOH}$. The importance of $\mathrm{MeOH}$ decomposition on the surface is supported by the fact that, if methyl formate is not obtained as product from $\mathrm{MeOH}$, $\mathrm{DMC}$ is also not observed as a product (such as for $\mathrm{Ag}$, for example). On Au electrodes, the formation of DMC takes place at potentials as low as $0.4 \mathrm{~V}$ showing that oxidative carbonylation of $\mathrm{MeOH}$ does not require metal ions (oxidized metal) as catalyst and that the reaction can take place directly on the metal, which represents ideal conditions for industrial applications as the catalyst stability is improved. These results represent an important step further in the development of an electrochemical process for the synthesis of DMC and can help the development of more efficient and selective processes for electrocarbonylation reactions.

\section{MATERIALS AND METHODS}

The experiments were performed using a spectroelectrochemical cell with a three-electrode configuration as described elsewhere. ${ }^{19,20}$ The working electrodes ( $\mathrm{Au}, \mathrm{Pd}, \mathrm{Pt}$, and $\mathrm{Ag}$ ) were discs mechanically polished with alumina suspension, rinsed with Milli-Q water (18.4 $\mathrm{M} \Omega$ ), and sonicated for $5 \mathrm{~min}$ before each experiment. A Pt coil was used as counter electrode and a $\mathrm{Ag} / \mathrm{AgCl}$ electrode as reference. The electrode potential was controlled with a Potentiostat 466 System (Model ER466) from E-DAQ. All the experiments were performed at room temperature.
The electrolyte solution was prepared with $0.1 \mathrm{M} \mathrm{LiClO}_{4}$ (Fluka, < 99\%) in methanol ( $\mathrm{MeOH}, 98 \%$ anhydrous from Sigma-Aldrich). Prior to the experiments, the solutions were purged with $\mathrm{Ar}$ (6.0 from Linde) to remove all the oxygen, and blank cyclic voltammograms were obtained. For the experiments with $\mathrm{CO}$, the solutions were fluxed with CO (6.0 Linde) for 20 min after oxygen removal. During the electrochemical/spectroelectrochemical measurements, the gas flow was kept in the cell atmosphere. For the isotopically labeled experiments, $\mathrm{CO}$ with ${ }^{13} \mathrm{C}>99 \%$ from Cambridge Isotope laboratories was used.

In-situ Fourier transform infrared (FTIR) spectroscopy (Bruker Vertex $80 \mathrm{~V}$ IR spectrophotometer) was used to characterize the products and intermediates of the reaction. $\mathrm{A} \mathrm{CaF}_{2}$ prism bevelled at $60^{\circ}$ was used, and the spectra correspond to an average of 100 interferograms with $8 \mathrm{~cm}^{-1}$ resolution and p-polarized light. The experiments were performed in thin-layer configuration, where the working electrode was pressed onto the prismatic window at a controlled potentential. After that, a reference spectrum was obtained and subtracted from the spectrum acquired at the sample potential. All the spectra in this work are presented as absorbance, according to $A=$ $-\log \left(R / R_{0}\right)$, where $R$ and $R_{0}$ are the reflectance corresponding to the single-beam spectra obtained at the sample and reference potentials, respectively. As a consequence, positive (negative) bands correspond to species present (absent) at the sample potential.

\section{ASSOCIATED CONTENT}

\section{Supporting Information}

The Supporting Information is available free of charge on the ACS Publications website at DOI: $10.1021 /$ jacs.7b08208.

Transmission spectra for species in solution (PDF)

\section{AUTHOR INFORMATION}

\section{Corresponding Author}

*m.koper@lic.leidenuniv.nl

ORCID

Marc T. M. Koper: 0000-0001-6777-4594

Present Address

${ }^{\S}$ Marta C. Figueiredo: University of Copenhagen, Department of Chemistry Nano-Science Center Universitetsparken, 52100 Copenhagen, Denmark.

Notes

The authors declare no competing financial interest.

\section{ACKNOWLEDGMENTS}

The authors acknowledge Covestro Deutschland AG for the financial support of this project.

\section{REFERENCES}

(1) Frontana-Uribe, B. A.; Little, R. D.; Ibanez, J. G.; Palma, A.; Vasquez-Medrano, R. Green Chem. 2010, 12 (12), 2099-2119.

(2) Keller, N.; Rebmann, G.; Keller, V. J. Mol. Catal. A: Chem. 2010, 317 (1-2), 1-18.

(3) Delledonne, D.; Rivetti, F.; Romano, U. Appl. Catal., A 2001, 221 (1-2), 241-251.

(4) Kuwertz, R.; Gonzalez Martinez, I.; Vidaković-Koch, T.; Sundmacher, K.; Turek, T.; Kunz, U. Electrochem. Commun. 2013, 34, 320-322.

(5) Filardo, G.; Galia, A.; Rivetti, F.; Scialdone, O.; Silvestri, G. Electrochim. Acta 1997, 42 (13-14), 1961-1965.

(6) Engeldinger, J.; Domke, C.; Richter, M.; Bentrup, U. Appl. Catal., A 2010, 382 (2), 303-311.

(7) Zhang, Y.; Bell, A. T. J. Catal. 2008, 255 (2), 153-161.

(8) Xu, B.; Madix, R. J.; Friend, C. M. J. Am. Chem. Soc. 2011, 133 (50), 20378-20383. 
(9) Yanji, W.; Xinqiang, Z.; Baoguo, Y.; Bingchang, Z.; Jinsheng, C. Appl. Catal., A 1998, 171 (2), 255-260.

(10) Han, M. S.; Lee, B. G.; Suh, I.; Kim, H. S.; Ahn, B. S.; Hong, S. I. J. Mol. Catal. A: Chem. 2001, 170 (1-2), 225-234.

(11) Yang, P.; Cao, Y.; Hu, J.-C.; Dai, W.-L.; Fan, K.-N. Appl. Catal., A 2003, 241 (1-2), 363-373.

(12) Sato, Y.; Kagotani, M.; Yamamoto, T.; Souma, Y. Appl. Catal., A 1999, 185 (2), 219-226.

(13) Funakawa, A.; Yamanaka, I.; Otsuka, K. J. Phys. Chem. B 2005, 109 (18), 9140-9147.

(14) Funakawa, A.; Yamanaka, I.; Otsuka, K. J. Electrochem. Soc. 2006, 153 (4), D68-D73.

(15) Jia, G.; Zhang, W.; Jin, Z.; An, W.; Gao, Y.; Zhang, X.; Liu, J. Electrochim. Acta 2014, 144, 1-6.

(16) Housmans, T. H. M.; Wonders, A. H.; Koper, M. T. M. J. Phys. Chem. B 2006, 110 (20), 10021-10031.

(17) Aurbach, D.; Chusid, O. J. Electrochem. Soc. 1993, 140 (11), L155-L157.

(18) Koper, M. T. M.; Lai, S. C. S.; Herrero, E. Mechanisms of the Oxidation of Carbon Monoxide and Small Organic Molecules at Metal Electrodes. In Fuel Cell Catalysis; Koper, M. T. M., Ed.; John Wiley \& Sons, Inc.: Hoboken, NJ, 2008; pp 159-207.

(19) Iwasita, T.; Nart, F. C.; Rodes, A.; Pastor, E.; Weber, M. Electrochim. Acta 1995, 40 (1), 53-59.

(20) Xia, X. H.; Liess, H. D.; Iwasita, T. J. Electroanal. Chem. 1997, $437(1-2), 233-240$. 